\title{
Escolher uma especialidade médica em Portugal
}

Rui Nogueira*

$\mathrm{O}$ jovem licenciado em Medicina escolhe uma especialidade depois de cumprir o primeiro ano de internato médico e seis anos de faculdade. É uma tarefa difícil para a maioria dos jovens colegas. Quase todos nós já passamos por esse momento. É uma opção de vida e para a vida.

Além da especialidade em si mesmo é também necessário escolher o local de formação e saber quais as condições de recepção e apoio e as evoluções esperadas. E como se não bastasse, precisa responder a outras perguntas: o que fazer com esta especialidade daqui a quatro ou cinco anos? E onde? E com quem? E como? E porquê? E para quê? Intuitivamente é natural que um jovem com menos de 30 anos pense no futuro e passe por estas e outras dúvidas.

Já ouvimos algumas ficções a jovens candidatos a Medicina, mas rapidamente se desvanecem nos primeiros anos de faculdade. Na faculdade fragmentamos o conhecimento desde o primeiro dia. Partimos todo o saber das ciências básicas e das clínicas de modo a facilitar a aquisição dos conceitos, quase sempre sem pessoa e sem doente, longe da realidade e sem entender que se gravita numa galáxia distante da vida real.

O princípio da fragmentação como redução mutilante do pensamento pode ser contrariado pelo princípio de complexidade que se estabelece como desafio e motivação para pensar. ${ }^{1}$ A aceitação da interdisciplinaridade dá origem a um diálogo entre saberes, realçando a necessidade de integrar conhecimentos aqduiridos em separado. Porém, a capacidade de integração do conhecimento e de reconhecimento prático e real carece de tempo e é em si mesmo um novo saber. É necessário que o jovem médico tenha perspicácia, maturidade e agilidade para ser médico em toda a sua plenitude.

O momento da escolha de especialidade surge precocemente no desenvolvimento da consciência médica. Será fácil um médico com poucos anos de experiência es-

*Coordenador do Internato de Medicina Geral e Familiar da Zona Centro. colher uma especialidade integradora, holística, centrada na pessoa?

A fragmentação do doente em doenças tem o perigo de ver o conjunto real como a simples soma das partes. «Para evitar o abuso da tecnologia e a fragmentação do doente é necessário um médico de família prestigiado, competente e polivalente». ${ }^{2}$ Existe a crença predominante de julgar os Cuidados de Saúde Primários (CSP) como básicos e simples. Nada pode estar mais longe da verdade. $^{3}$

A visão hospitalocêntrica das velhas escolas médicas e a afirmação e prestígio das especialidades hospitalares protegidas pela instituição grandiosa que deslumbra os profissionais de saúde e tem visibilidade na sociedade e na comunicação social marca de forma indelével o trajecto do estudante de Medicina. É assim há décadas. $\mathrm{O}$ estudante de Medicina tem a cabeça feita no fim do curso. O Professor Jorge Galperin contrapôs-me esta ideia. Dizia-me com a sabedoria da sua simplicidade que os estudantes chegam ao fim do curso não com a cabeça feita mas com a cabeça desfeita! «Aprender a ser médico num hospital é assim como aprender a ser veterinário num jardim zoológico» - dizia ele. «Aprende-se a ver girafa, leão, macaco... mas na vida prática precisam ver cão, vaca, cavalo...»

Temos consciência que à saída da faculdade o jovem licenciado em Medicina ainda não é médico. No final do primeiro ano de internato poderá ser um médico pluripotencial - como uma célula indiferenciada à procura de especificidade e de função. Nesta altura o jovem médico começa a fazer a integração dos conhecimentos médicos no contexto da prática e na relação com a pessoa, «avaliando o papel dos múltiplos e interactivos determinantes da doença e da saúde». ${ }^{3}$

É nesta fase que o jovem médico é chamado a escolher uma especialidade. Diferentes influências ditam as regras na escolha. Num texto memorável de 1987, Vítor Ramos faz uma resenha histórica da criação da especialidade e das influências dos contextos da época. ${ }^{4} \mathrm{~A}$ partir da década de 60 e depois na de 70 o modelo reducio- 
nista tecnológico predominante do meio hospitalar era posto em causa de tal forma que se gerou um movimento internacional em prol do desenvolvimento da Medicina Geral e Familiar (MGF). E aponta marcos históricos deste movimento:

1. A fundação do colégio de clínicos gerais britânicos (1952);

2. As primeiras propostas para a criação da especialidade nos EUA e no Canadá (1966);

3. O reconhecimento como $20 .^{a}$ especialidade da medicina americana (1969);

4. A criação da primeira cátedra de clínica geral no Reino Unido (1970);

5. A fundação da WONCA (1972);

6. A definição de um perfil para o clínico geral europeu, proposto pelo grupo «Leeuwenhorst» (1974);

7. O reconhecimento pela $30 .{ }^{a}$ Assembleia Mundial de Saúde que a maior parte dos sistemas de saúde do mundo não estava a dar resposta aos problemas e necessidades de saúde das populações (OMS 1977);

8. A Conferência Internacional sobre CSP, Alma Ata (1978);

9. O aparecimento de livros de texto e de classificações sobre problemas de saúde no âmbito dos CSP e de MGF (WONCA 1979);

10. O início da obrigatoriedade da formação pós-graduada específica para o exercício de MGF (The New Leeuwenhorst Group, 1985).

É pouco provável que os jovens médicos tenham conhecimento da história e do crescimento e surgimento das especialidades médicas.

Uma declaração política da UEMO (União Europeia de Clínicos Gerais/Médicos de Família) realça diferentes razões para a falta de médicos de família em vários países: ${ }^{5}$

a) Problemas no recrutamento;

b) Deficiências no ensino e treino universitário;

c) Más condições de trabalho;

d) Colisão com o estilo de vida moderno;

e) Percebida falta de «status» do MF.

Apesar de ser uma declaração com cinco anos, não se vislumbra uma evolução significativa.

Em 2002 a Associação Portuguesa dos Médicos de Clínica Geral publicou uma reflexão «Medicina Geral e Familiar: colapso ou ressurgimento?» onde faz salientar o problema da falta de médicos de família e a necessidade de desenvolver uma estratégia de resolução. ${ }^{6}$ «Não basta apregoar a filosofia, os valores e a importância da MGF e dos CSP se, na prática, não surgirem medidas e incentivos concretos para a promover, credibilizar e dignificar. O objectivo final é o de conseguir captar para MGF os melhores jovens médicos, em especial os mais vocacionados para a prática médica desta especialidade».

Um estudo original publicado nesta edição da Revista Portuguesa de Clínica Geral pretende fazer uma avaliação da influência dos factores identificados para a escolha de MGF e analisar a importância de factores intrínsecos à especialidade numa população de internos de MGF.7 É um estudo observacional, transversal e analítico que conclui «haver uma evolução positiva do padrão de escolha» e que a opção por MGF é maioritariamente centrada em motivações intrinsecamente relacionadas com a especialidade, aparentando ser mais que uma «alternativa de recurso».

Num outro estudo da mesma autora versando sobre a mesma população de internos são referidos $78,90 \%$ que apontaram a MGF como sendo a sua prioridade de escolha. $^{8}$

As organizações profissionais e científicas de médicos de família deveriam desenvolver "músculo" e poder político para influenciar o crescimento de MGF. Um bom indicador de êxito seria conseguirem um atractivo renovado para a especialidade. ${ }^{2}$

\section{REFERÊNCIAS BIBLIOGRÁFICAS}

1. Batista IL, Salvi RF. Perspectiva pós-moderna e interdisciplinaridade educativa: pensamento complexo e reconciliação integrativa. Ensaio 2006; 8 (2): 147-159.

2. Gérvas J, Starfield B, Minué S, Violan C; Seminario de Innovación en Atención Primaria. Algunas causas (y soluciones) de la pérdida de prestigio de la medicina general/de familia. Contra el descrédito del héroe. Aten Primaria 2007 Nov; 39 (11): 615-8.

3. Primary Care: balancing health needs, services, and technology. New York: Oxford University Press; 1998.

4. Ramos, V. O ressurgimento da Medicina Familiar. Rev Crit Cien Sociais 1987 Set; 23: 157-67.

5. UEMO. O futuro da mão-de-obra dos médicos de Família: Declaração política da UEMO. Rev Port Clin Geral 2006 Set-Out; 22 (5): 647-9.

6. Medicina Geral e Familiar: colapso ou ressurgimento? Lisboa: Associação Portuguesa de Médicos de Clínica Geral; 2002.

7. Gaspar D. Escolher a especialidade de Medicina Geral e Familiar: opção inicial ou uma alternativa? Rev Port Clin Geral 2010 Jul-Ago; 26 (4): 354-68.

8. Gaspar D. Internato Médico de Medicina Geral e Familiar: quem somos? O perfil do interno MGF. Acta Med Port 2010 Jan-Fev; 23 (1): 3950.

O autor declara não possuir quaisquer conflitos de interesses. 